\title{
Residual Stresses and Cracks in Forgings of Heat-treatable Aluminium Alloys
}

\author{
Jan Luštinec ${ }^{1,2}$, Vladivoj Očenášek ${ }^{1}$ \\ ${ }^{1}$ SVÚM a.s., Tovární 2053, 25088 Čelákovice. Czech Republic. E-mail: lustinec@svum.cz, ocenasek@svum.cz, \\ ${ }^{2}$ University of Chemistry and Technology Prague, Department of Metals and Corrosion Engineering, Technická 5, 16628 \\ Prague 6, Czech Republic.
}

\begin{abstract}
The heat treatment of the heat-treatable aluminium alloy forgings includes cooling from the solutionising temperature. After heat treatment, residual stresses remain in the forging, which are due to temperature gradients during cooling. The effect of these residual stresses on the forging properties can be significantly influenced by other technological operations, including artificial aging, machining, and surface treatments. The influence of the surrounding environment can also play an important role. Because in connection with the residual stresses after heat treatment we often encounter cracks in forgings, this paper is devoted to an overview of factors that influence cracks. The typical examples of damaged forgings are discussed and explained the circumstances that caused cracks under the influence of residual stresses.
\end{abstract}

Keywords: forging, aluminium alloys, heat treatment, residual stress, crack

\section{Introduction}

Heat-treatable aluminium alloys are widely used in automotive for demanding components. In the field of hot forming alloys, they are used for rolled products, extruded profiles and rods and die or open die forged products. Final properties are achieved by heat treatment, which includes solutionising soak at a high temperature followed by rapid cooling above a critical rate. When cooling due to temperature gradients, residual internal stresses remain in the products. In the case of sheets, plates and pressed products, these residual stresses can be relatively easily eliminated or minimized by a small plastic deformation. Since this is not always possible in the case of forgings, we often encounter the consequences of these residual stresses in practice. Particularly in the case of larger forgings, the complete removal of residual stresses and their consequences is difficult. Therefore it is necessary to take into account the residual stress and adapt the technological parameters of the production accordingly. Some heat-treatable alloys are less sensitive to these stresses, some alloys are more sensitive. Among the less sensitive are Al-Mg-Si alloys (6XXX), the more sensitive are alloys containing copper (2XXX, 7XXX). The stresses generated during cooling from the solutionising temperature cause changes in the shape of the product and after cooling the residual stresses are a potential source of cracking. The occurrence of these cracks depends on a number of other technological factors. This paper deals in detail with all the major factors that influence cracks in forgings and illustrates the effects of these factors on specific cases of forgings of 7075, 2024 and 2017 alloys.

\section{Factors influencing residual stresses in for- gings}

In contrast to the residual tensile stresses that occur on the surface of the products during cold plastic deformation, the residual stresses after heat treatment are compressive on the surface and tensile inside. Since these residual stresses can reach the yield strength, they can lead to cracks and thus to product failure. The formation of cracks under the influence of residual stresses is influenced by a number of other factors, including the method of cooling from the solution temperature [1], the shape and size of the forging, the anisotropy of the structure [2], the type of alloy, the choice of heat treatment parameters $[3,4,5]$, machining, corrosion environment, and time factor. In addition, the basic characteristics of the influence of these factors are presented in terms of forging technology.

a) Cooling from the solution temperature is usually carried out in water. The cooling rate depends on the water temperature and the shape and size of the forging. As the water temperature decreases, the residual stresses also increase. Their removal or minimization is possible with forgings either by plastic deformation in the die or by increasing the water temperature. The artificial aging temperature is low to substantially eliminate internal stresses [3], or an extremely long time at the aging temperature is required [4]. The influence of cooling water temperature on residual stresses after heat treatment has been discussed by many authors in aluminium alloys, especially in the case of large forgings. In the paper [1], the authors deal with airscrew hub forging of 2014 T6 alloy. In the work, reference is made to US specification MIL-H-6088G for heat treatment of forgings. The specification recommends a water temperature of 60 to $82{ }^{\circ} \mathrm{C}$ for cooling from solution temperature $\left(496\right.$ to $\left.507^{\circ} \mathrm{C}\right)$. The greatest surface compressive stresses in the range of 112 to $148 \mathrm{MPa}$ were measured at a water temperature of $60{ }^{\circ} \mathrm{C}$, which is at the $\mathrm{R}_{\mathrm{p} 0.2}$ limit of the material at the time of cooling. In the paper [6], the authors dealt with the measurement of internal stresses after heat treatment of forged block 
1000x550x24 mm from alloy 7449 (AlZn$\mathrm{MgCu}$, solution temperature $470{ }^{\circ} \mathrm{C}$ ). The residual tensile stresses in the centre of the body reached the value of $350 \mathrm{MPa}$. For larger forgings, it is therefore necessary to choose a water temperature above $40^{\circ} \mathrm{C}$, or use higher temperatures, or in extreme cases boiling water. The favourable effect of higher water temperature is to minimize the shape changes of forgings. When increasing the water temperature and thus decreasing cooling rate, it is necessary to count with a negative influence on mechanical properties of forgings, eventually also on their corrosion resistance. In some cases, it is advisable to replace the water with another medium to minimize residual stresses [7, 8]. Uneven cooling of the forgings can occur under conditions when larger numbers of forgings in several layers are stacked one above the other in cooling containers. The forgings are otherwise cooled at the bottom and periphery of the container and otherwise forgings in the middle of the container. This may affect the magnitude of internal stresses in the forgings depending on its location in the container.

b) The shape and size of the forging have an important effect in cooling from the solution temperature. The magnitude and distribution of these residual stresses depends on the cooling rate and the shape of the product. In the case of round bars or products of regular shapes, the distribution in the bulk of the product is symmetrical (Fig. 1,2), in the case of more complex shapes such as forgings, the distribution of internal stresses is uneven. The uneven cooling rate in the forging parts therefore leads to an inhomogeneous distribution of the residual internal stresses in the bulk of the forging. In the case of parts with complex shapes, with both thin and thick sections, residual stresses can lead to significant deformation and change in the dimensions of the forging.

c) Machining of the forging is the most common operation, which is the immediate cause of cracks. Remove of surface layers from the forging leads to redistribution of internal stresses. In this way, tensile stresses can be applied to the surface, which determine the occurrence of cracks. If stress concentrators arise in the area of tensile stresses during machining, suitable con- ditions for crack formation are created. The formation and propagation of cracks can then be accelerated by inappropriate structure, operational loading of the part or the influence of the surrounding environment.

d) The type of alloy and the choice of heat treatment parameters and corrosive environment have a fundamental influence on the design of the component due to its conditions of use. Some aluminium alloys are highly sensitive to Stress Corrosion Cracking (SCC). Therefore, residual internal stresses also play an important role in these alloys. High-strength alloys of the 7XXX series $(7075,7010,7050)$ and alloys of the 2XXX series $(2014,2017,2024)$ are sensitive to SCC. An example of the most sensitive alloy is 7075 alloy. It is the strongest commercially used aluminium alloy. It achieves maximum mechanical properties in the heat treatment state T6, i.e. in the state where it has the worst corrosion properties [9]. Therefore, if the component is exposed to a corrosive environment, it is necessary to select other artificial aging parameters (T73, T74 or T76). However, a slight deterioration of the mechanical properties due to aging must be taken into account in this choice. In addition to the chemical composition, the state of heat treatment and the state of stress, the type and anisotropy of the structure have a significant influence on the SCC resistance.

e) Anisotropy of the structure has a significant role in corrosion resistance. In the case of forming aligned structures, the resistance to SCC is significantly affected and is directionally dependent. In cases where the residual tensile stresses are perpendicular to the fibre structure or flat recrystallized grains, the resistance to $\mathrm{SCC}$ is minimal. In Tab. 1, the SCC resistance rating of 7075 alloy in two heat treatment states is taken from [2]. The rating is based on a division into 4 groups marked A to $\mathrm{D}$. The best resistance is marked A, the worst $\mathrm{D}$. This evaluation shows a significant influence of heat treatment and orientation of the structure on SCC for various types of wrought structures of 7075 alloy. The choice of an over-aged state with lower mechanical properties prefers to T6 temper.

f) The "time factor" refers to the time periods between cooling from solution temperature and artificial aging, the time between production and delivery of the forging to the customer (storage), 
the time to machining and surface treatment, and the time to use of product. At these periods, the presence of internal stresses can cause or accelerate crack propagation. In these cases, there is often difficult to predict the time to crack formation. Therefore, these types of defects can have a large time scatter.

Tab. 1 Classification of resistance of 7075 alloy to SCC [2]

\begin{tabular}{|c|c|c|c|c|c|}
\hline Alloy/Temper & Orientation & Rolled products & Rods & Extrusions & Forgings \\
\hline \multirow{3}{*}{7075 T6 } & L & A & A & A & A \\
\cline { 2 - 6 } & LT & B & D & B & B \\
\cline { 2 - 6 } & ST & D & D & D & D \\
\hline \multirow{3}{*}{7075 T73 } & L & A & A & A & A \\
\cline { 2 - 6 } & LT & A & A & A & A \\
\cline { 2 - 6 } & ST & A & A & \\
\hline
\end{tabular}

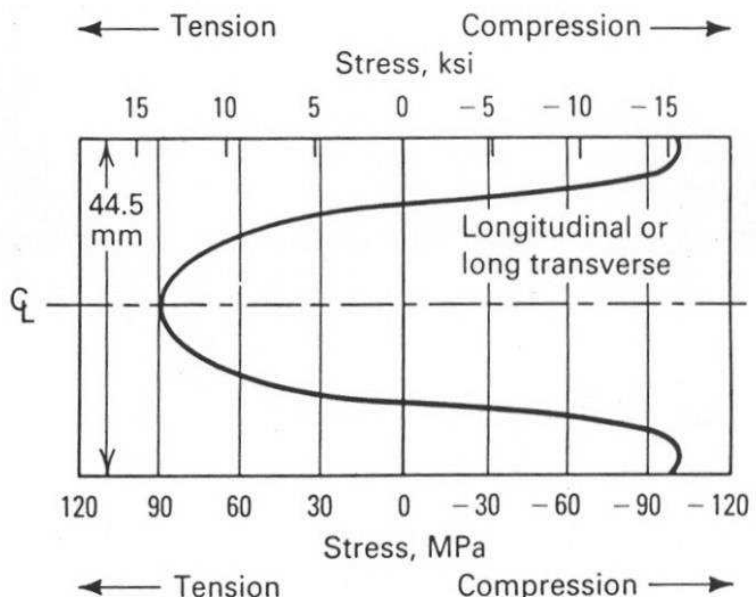

Fig. 1 Residual stresses after heat treatment of $44.5 \mathrm{~mm}$ diameter Al alloy rod [3]

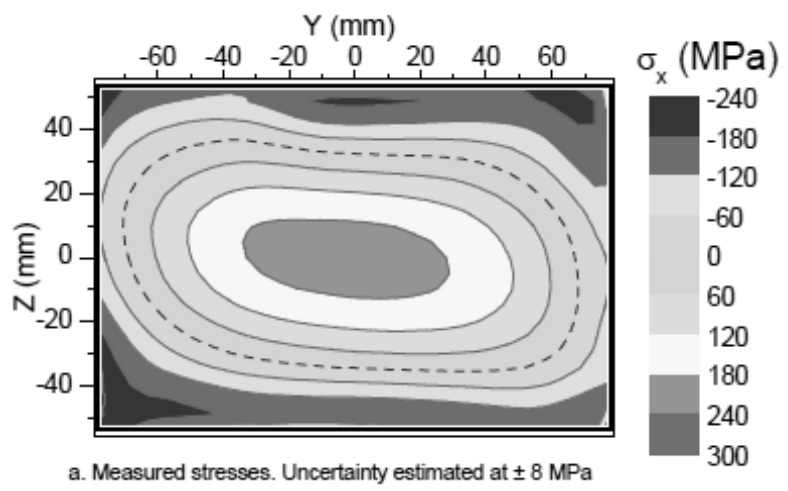

Fig 2 Measured residual stresses after heat treatment of forged 7050 T74 alloy block [10]

\section{Crack formation in forgings of heat-treatable aluminium alloys}

The following paragraphs give examples of 7075 , 2024 and 2017 forgings that have been cracked due to residual stresses after heat treatment.

\subsection{Die forging of a bicycle wheel hub from alloy 7075}

In the production of bicycles, heat-treatable alloys are used not only for wheel frames $(6061,6069,7005)$, but also for other components. One of the stressed parts is the wheel hub. In order to produce a hub with the highest possible mechanical properties, a 7075 alloy forging in the T6 temper was selected (Fig. 3). Longitudinal cracks formed in the wheel hub after heat treatment and machining at the constructional notch (Fig. 4). The combination of factors related to residual stress after heat treatment has been shown to cause cracks. The combination of the internal stress, the heat treatment applied to the corrosionsensitive state, the structure at the crack position and the design notch led to the SCC crack. Structure analyses have shown that the critical point for crack formation is the parting line of the forging, where the structure is unfavourably oriented (Fig. 5). In the parting line of the forging, an intensive material flow occurs and a significantly uneven coarse-grained recrystallized structure is formed. The orientation of these grains is such that the peripheral tensile residual stresses after heat treatment are the most sensitive combination of structure and stress for SCC formation. Corrosive attack of grain boundaries is also evident around the fracture surface (Fig. 6). In addition, the formation of cracks was affected by machining, where internal stresses were redistributed and tensile stresses occurred on the workpiece surface. Once the surface layers are under tensile stress, their sensitivity to SCC increases significantly. If an anisotropic structure is improperly oriented at these points, then there is a high probability that after some time a corrosion-induced crack will be initiated and possibly expanded under the influence of existing internal or operating stresses. The time of stress corrosion crack formation can vary over a relatively wide time span, depending on the above mentioned factors. This was indicated by the fact that some of the cracks appeared in the wheel hub during the final inspection and some cracks occurred later before assembly or when the finished product was stored (Fig. 4).

The crack analysis thus showed that when manufacturing the wheel hub of alloy 7075, due to the corrosion sensitivity of the T6 temper, it is necessary to increase the temperature of the water bath to $60{ }^{\circ} \mathrm{C}$ and to change the artificially ageing parameters to overaged $\mathrm{T} 73$ conditions, even at the cost of lower mechanical properties. 


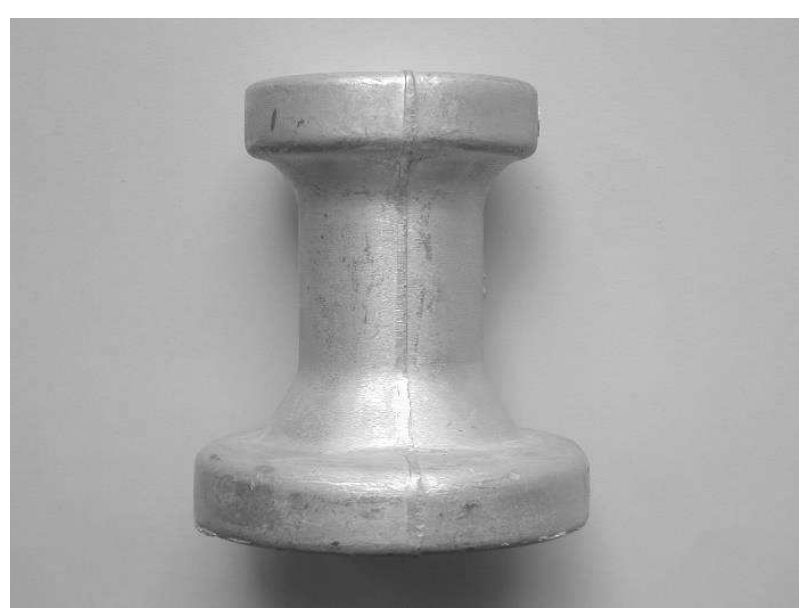

Fig. 3 The forging of bicycle wheel hub from alloy 7075

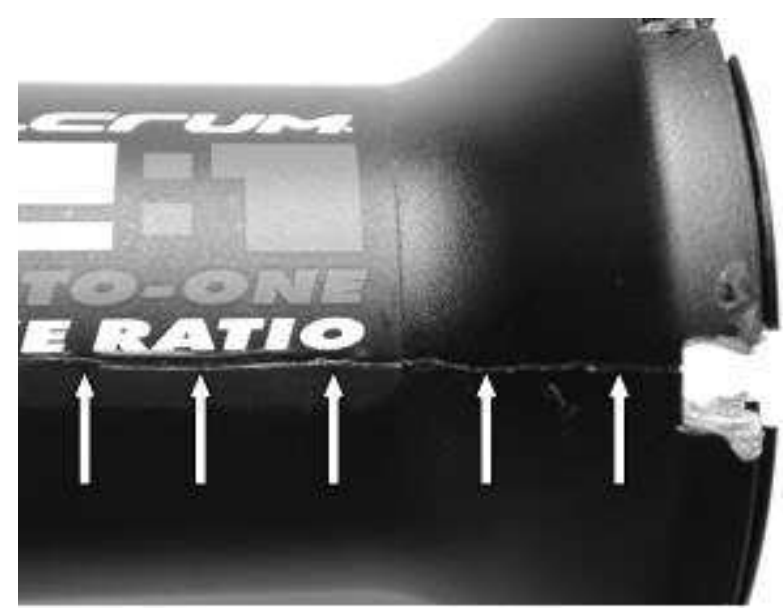

Fig. 4 The crack of the wheel hub at the parting line of the forging

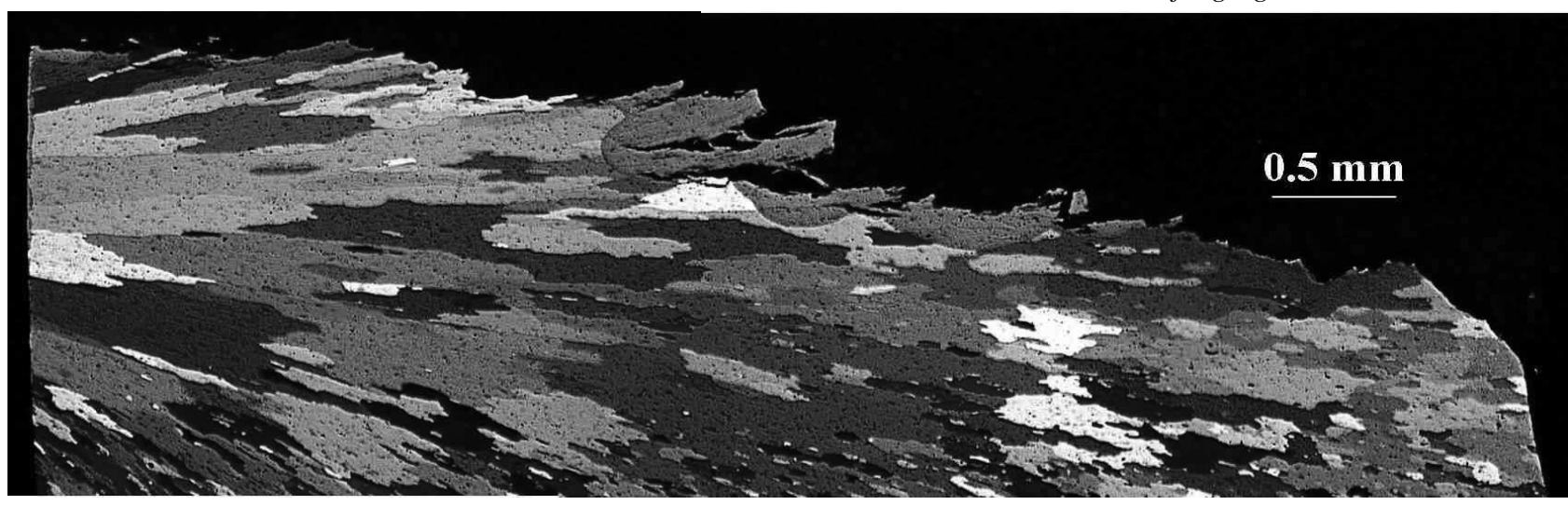

Fig. 5 SCC crack at the aligned structure in the parting line of the forging

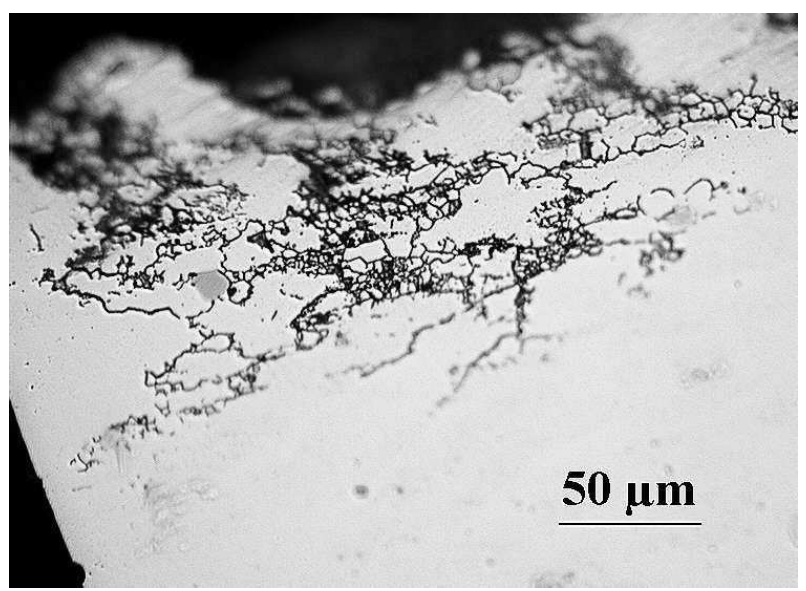

Fig. 6 Corrosive attack of grain boundaries around the fracture area

\subsection{Open die forging of propeller hub from alloy 2024}

The hub of propeller blade, from alloy 2024, is one of the larger forgings that cannot be forged in the die. Since they are forged from the cast bar, they are first annealed and thoroughly forged by cross-forging and upsetting with the punching of the mandrel. The forging is partially machined to reduce weight prior to heat treatment. Even after roughing, it is a robust forging, i.e. in terms of heat treatment, a forging in which relatively large temperature gradients arise during cooling from the solution tempera- ture. Uneven heat dissipation therefore leads to significant residual stresses. For heat treatment, it is therefore necessary to use a water temperature above $60{ }^{\circ} \mathrm{C}$ and to do so in a defined manner. Despite these precautions, the integrity of the forging may occur due to high internal stresses. In Fig. 7 shows a case in which a heat-treated and partially machined forging has been broken while machining.

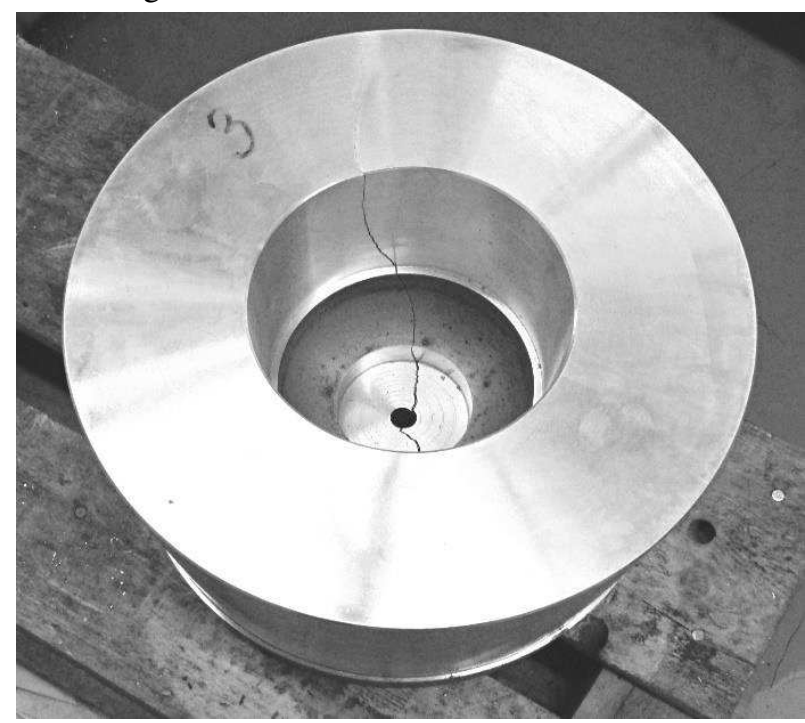

Fig. 7 Heat treated and partially machined propeller hub forging cracked during $\mathrm{CNC}$ machining 
The crack formation and its gradual expansion occurred due to the notch effect that occurred during machining in the area of tensile stress (Fig. 8). The high level of residual stresses is indicated by the expansion of the crack to almost the outer surface of the forging. Minor intergranular cracks were observed on the machined surface near the main crack (Fig. 9). The dendritic segregation (inhomogeneity of the chemical composition) is evident in the grains, which indicates incomplete annealing of the cast bars. The preserved and undeformed cast structure and the locally increased amount of intermetallic phases at the grain boundaries thus significantly weaken the grain boundaries and are then an easy site for the formation and propagation of cracks.

Thus, the reason for the failure of the analysed piece of propeller hub was probably the concurrence of the insufficiently homogenized initial structure of the cast bar, the undeformed structure in the middle part of the forging and the high level of residual stresses. Although in the case of large forgings it is always necessary to count with a certain level of residual stresses after heat treatment, it is necessary to minimize these stresses by maintaining a sufficiently high cooling water temperature ( $\min .60^{\circ} \mathrm{C}$ ) and to ensure a stable position of the forging while cooling from the solution annealing temperature to ensure uniform residual stresses.

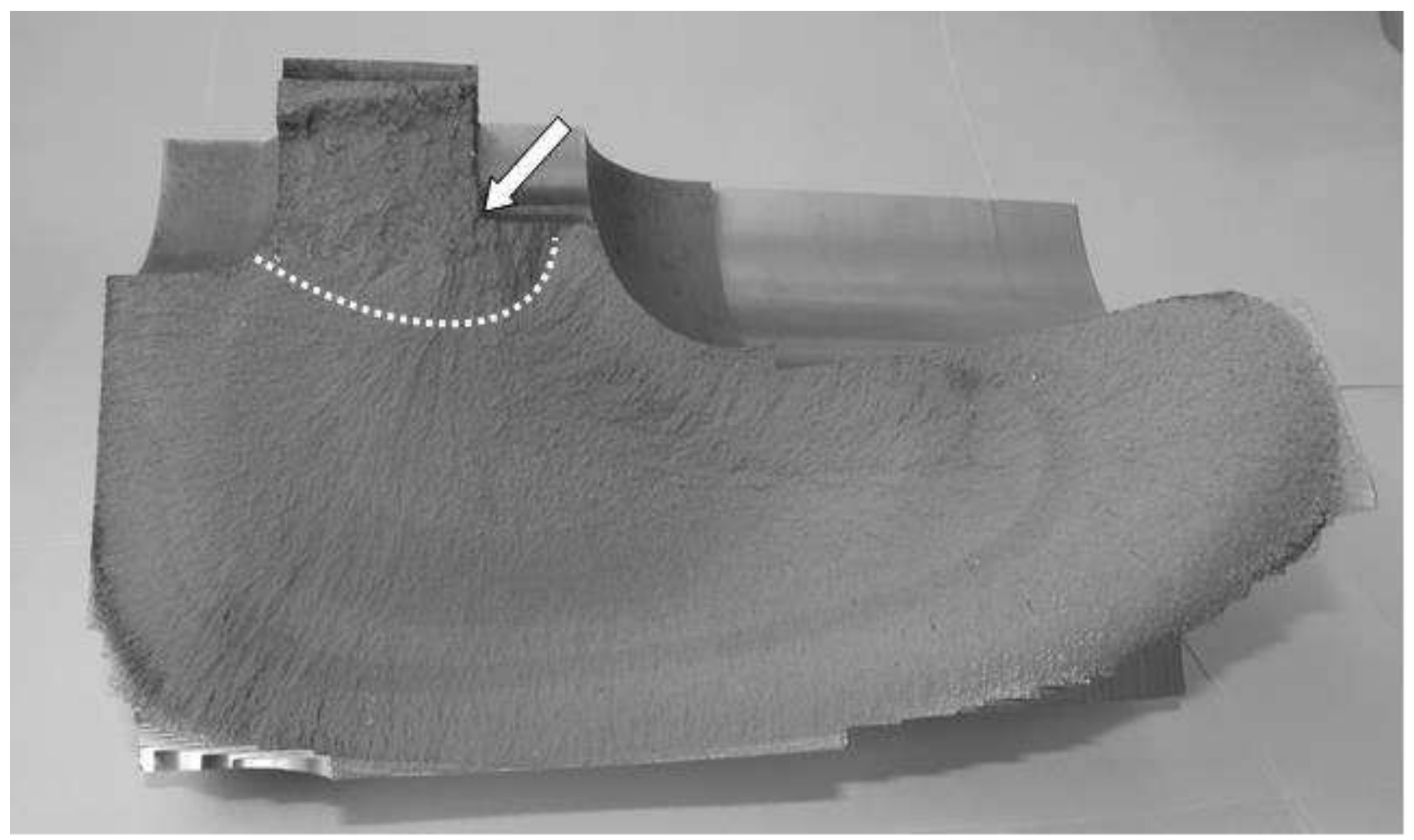

Fig. 8 The fracture surface of the hub with the location of the crack formation and marked the area from which the crack expanded. Crack propagation is apparent.

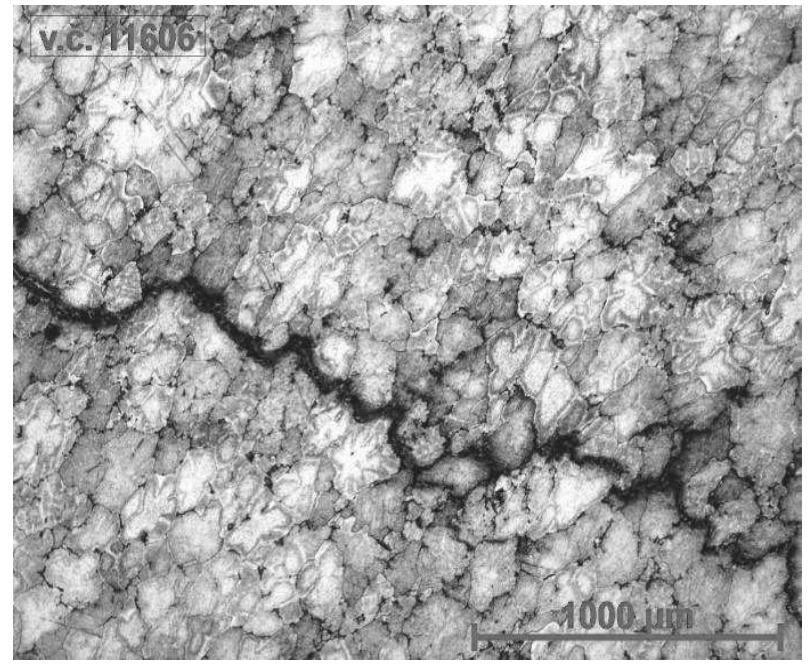

Fig. 9 Intergranular minor crack with undeformed cast grains

\subsection{Propeller blade die forging from 2017 aluminium alloy}

Aluminium alloy 2017 propeller blades are technologically demanding die forgings. Due to the length of the forging and the shape changes along the forging, uneven residual stresses occur during cooling from the solution annealing temperature. These residual stresses lead to deformations of the forging. Therefore are forgings straightened in the die after heat treatment. Nevertheless, cracks may occur as a result of residual stresses. When cooling, compression stresses are created on the surface, tensile stresses are in the middle of the forging. The unevenness of these stresses at different locations of the propeller blade is related to the changing cross-section of the propeller blade and different heat dissipation from the forging. Residual stress redistribution occurs during die straightening and subsequent machining. The original tensile stresses inside the forging thus reach its surface. A 
typical position of the crack is at the blade root (Fig. 10). The crack is formed in the longitudinal axis in the thread of the rotationally symmetrical root. The crack does not continue to the leaf. The formation of a crack is also influenced by the structure, which occurs during forging in the die. The crack is always oriented so that it points to the region of the flash in the parting plane of the die forging. The formation and propagation of the intergranular crack (Figs. 11 and 12) are thus facilitated and controlled by the nature of the anisotropic recrystallized structure where the grain boundaries in the region of the parting plane are unfavourably oriented towards residual internal stresses. Since in the direction perpendicular to the elongated flat grains lower mechanical properties and lower plasticity have to be taken into account, the grain structure determines both the location and the direction of crack propagation. The region of the flash in the parting plane is therefore a critical point for the preferential crack formation. A crack can occur either during or after machining. The time to crack formation after machining cannot be estimated in advance. The crack may be formed immediately or during storage. Both the magnitude of the internal stresses and the anisotropic structure and the influence of the storage environment play a role in the crack formation. AlCu4MgSi (2017) alloy is an SCC sensitive alloy. Minimizing residual stresses from heat treatment is therefore essential to prevent cracking after machining. Such cracks can only be prevented or reduced by maintaining a sufficiently high cooling water temperature and by providing a defined way of cooling the propeller blade when immersed in water.
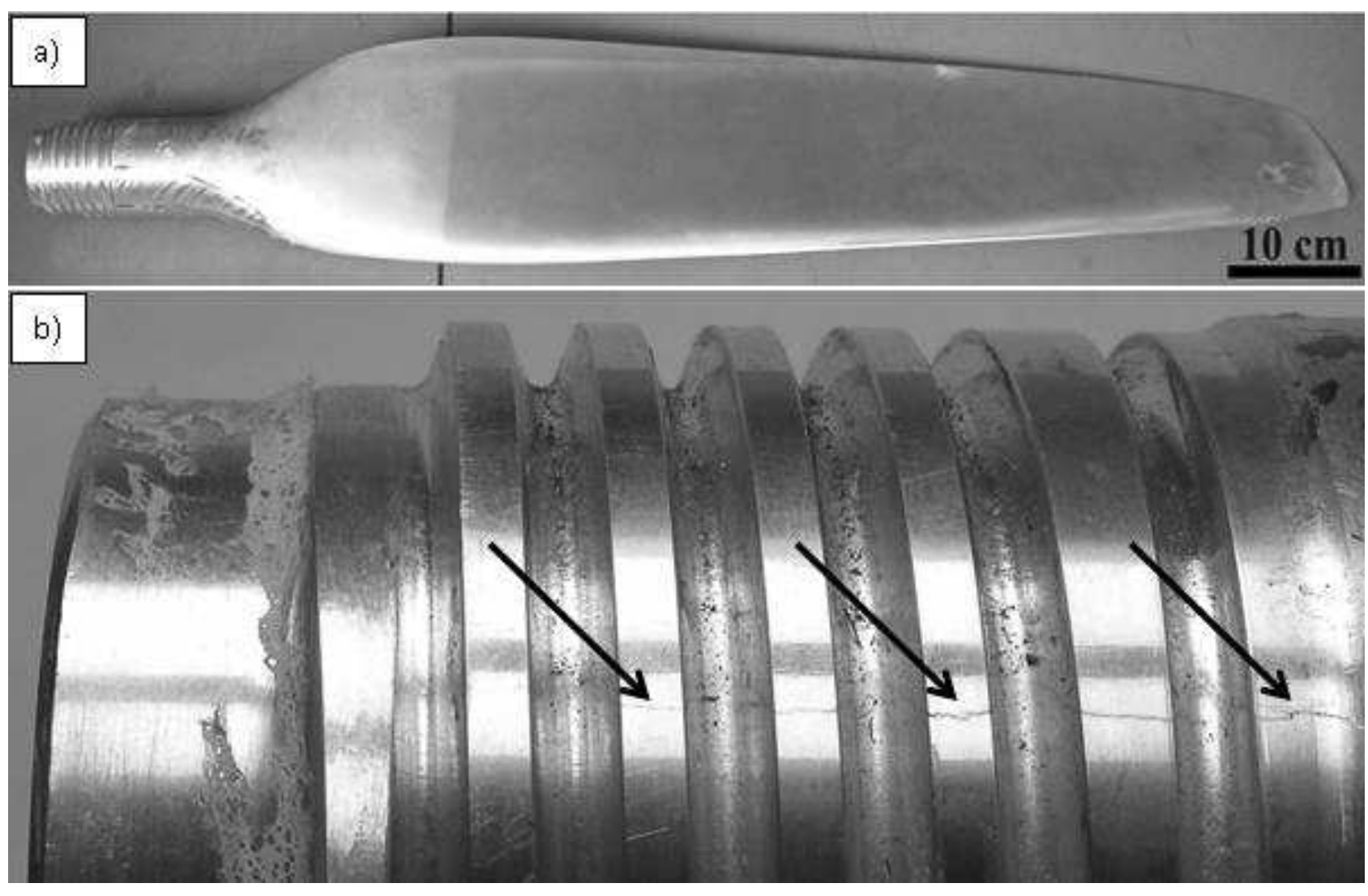

Fig 10 Propeller blade forging (a) and detail view of the threaded root with crack on the surface (b)

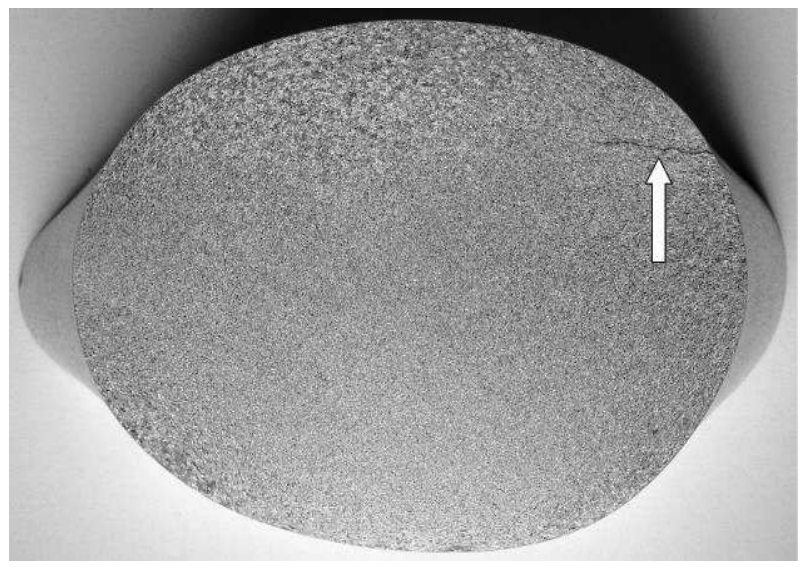

Fig. 11 The crack in the transition of the threaded root into the blade

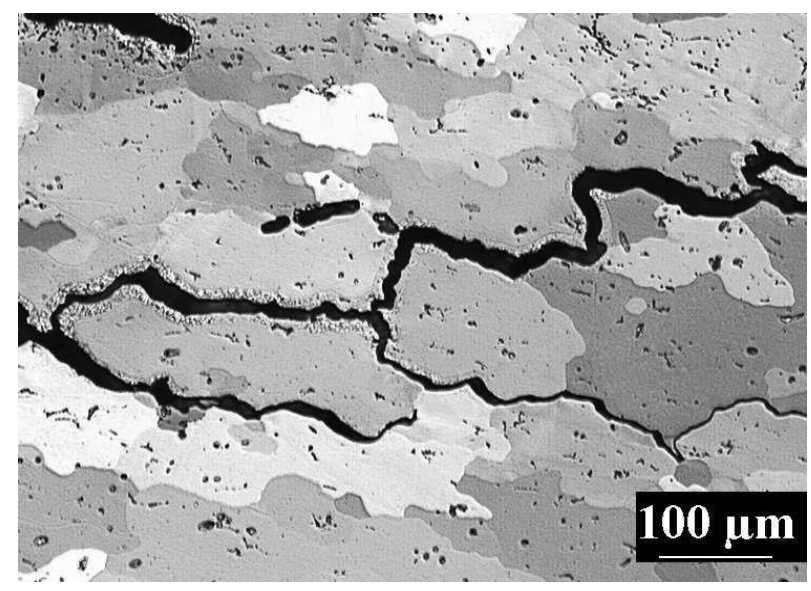

Fig. 12 Intergranular crack propagation 


\section{Conclusion}

The contribution is focused on residual stresses and cracks arising after heat treatment of forgings from heattreatable aluminium alloys. In connection with the choice of alloy type, influence of heat treatment parameters, machining and environmental influence, the causes of cracks in real forgings from 7075, 2024 and 2017 alloys are discussed.

\section{Acknowledgement}

The results presented in this paper were created with the financial support of TA $\breve{C} R$ within the framework of the projects No. TA02011137 and TH03010255.

\section{References}

[1] TANNER, D.A., ROBISON, J.S. (2008). Reducing residual stress in 2014 aluminium alloy die forgings. In: Materials and Design, Vol. 29, Issue 7, pp. 1489-1496.

[2] ASTM G64 - Classification of Resistance to Stress-Corrosion Cracking of High-Strength Aluminium Alloys, In: Annual Book of ASTM Standards, American Society for Testing and Materials.

[3] Heat treating of aluminium alloys. In: ASM handbook, Vol. 4, pp. 841-879, Tenth edition. ASM International.

[4] CINA, B., KAATZ, T., ELDROR, I. (1990). The effect of heating shot peened sheets and thin plates of aluminium alloys. In: Journal of materials science, Vol. 25, pp. 4101-4105.

[5] SOBOTKA, J., SOLFRONK, P., KOLNEROVA, M., KORECEK, D. (2018). Influence of technological parameters on ageing of aluminium alloy AW-2024. In: Manufacturing Technology, Vol. 18, Issue 6, pp. 1023-1028.

[6] ROBITSON, J.S. (2009). Influence of cold compression on the residual stresses in 7449 forgings. In: JCPDS-International Centre for Diffraction data 2009, ISSN 1097-0002.

[7] NICOL, J.A., SEATON, E.D., KUHLMAN, G.W., Yu, H., PISHKO, R. (1996). New quenchant for aluminium. In: Advanced materials and processes, Vol. 149, Issue 4, pp. 40S-40V.

[8] FLETCHER, A.J. (1989). Thermal Stress and Strain Generation in Heat Treatment. Elsevier Applied Science, London and New York.

[9] KUČERA, V., VOJTĚCH, D. Influence of the heat treatment on corrosion behaviour and mechanical properties of the AA 7075 alloy. (2017). In: Manufacturing Technology, Vol. 17, Issue 5, pp. 747-752.

[10] PRIME, M.B., NEWBORN, M.A., BALOG, J.A. (2003). Quenching and cold-work residual stresses in aluminum hand forgings: Contour method measurement and FEM prediction. In: Materials Science Forum, Vols. 426-432, pp. 435-440. 